\title{
Collaborative Deformation Design Using Control Integrated Analysis Methods for Hypersonic Waverider
}

\author{
Yanbin Liu ${ }^{1,2}$ and Yuping $\mathrm{Lu}^{2}$ \\ ${ }^{1}$ State Key Laboratory of Virtual Reality Technology and Systems, Beihang University, Beijing 100191, China \\ ${ }^{2}$ College of Astronautics, Nanjing University of Aeronautics and Astronautics, Nanjing 210016, China \\ Correspondence should be addressed to Yanbin Liu; nuaa_liuyanbin@139.com
}

Received 21 December 2014; Revised 21 March 2015; Accepted 23 March 2015

Academic Editor: N. Ananthkrishnan

Copyright (c) 2015 Y. Liu and Y. Lu. This is an open access article distributed under the Creative Commons Attribution License, which permits unrestricted use, distribution, and reproduction in any medium, provided the original work is properly cited.

\begin{abstract}
Hypersonic waveriders have a large flight envelope, leading to the difficulty in keeping overall flight stability for a fixed geometry. Accordingly, hypersonic waveriders can be considered to design as a morphing vehicle such that the flight range is expanded for waveriding stability. To this end, this paper investigates the collaborative deformation design using control integrated analysis methods for the hypersonic waverider. Firstly, a parametric model is applied to combine the shape deformation with the geometrical properties. Secondly, the morphing process with regard to the change in a single geometric parameter and the static and dynamic characteristics affected by this deformation are analyzed. Afterwards, the collaborative relations are discussed for the changes in the lower forebody angle and elevon area. Furthermore, a flight control law is designed to guarantee flight stability while implementing the collaborative deformation, and the morphing results are evaluated based on the control-oriented idea. Finally, a simulation example is used to verify the effectiveness of the proposed methods for the hypersonic waverider.
\end{abstract}

\section{Introduction}

Interest in hypersonic vehicles has origins in two main applications. The first is to provide a reliable and cheap way to space. The second is to realize a fast response to potential threats around the globe [1]. Typically, hypersonic vehicles are characterized by long, slender geometries with highly coupled engines and airframes [2], and such configurations make that the vehicle model is nonlinear, multivariable, and strong coupling and includes complicated dynamics and uncertain parameters [3]. More importantly, hypersonic vehicles are sensitive to flight conditions and states such as the dynamic pressure and angle of attack; as a result, deviating from the design point will lead to the deterioration of waveriding performances [4]. To this end, hypersonic vehicles can be considered to apply the morphing technologies for the purpose of enhancing the overall performance.

Recently, the trade-off studies are paid more attention for the control-oriented design of hypersonic vehicles. This is due to the presence of the complex interactions in a hypersonic vehicle, involving aerodynamics, propulsion, control, and so on. Meanwhile, the highly integrated dynamics of the hypersonic vehicle require a tightly integrated design process [5]. Therefore, the considerations of the control-related tradeoff design will assist to impose serious compromises in both system cost and quality of overall performance for hypersonic vehicles [6]. In particular, the influence of elevator size and placement on control-relevant static properties and dynamic properties are analyzed in [7], and the resulting investigation shows the trade-off design is required in relation to saturation constraints. Beyond this, the modelling and analysis framework is given for the trade-off design in [8], and a suite of integrated multidisciplinary modelling tools is developed to contribute to the control-relevant analysis and design for hypersonic vehicles to maximize overall stability and performance. Furthermore, the Aerospace Systems Modelling and Analysis Program-Hypersonic version (ASAP-HYP) tool suite is designed and used in [9], and this tool allows for the rapid modeling and analysis ability during early stages of the hypersonic vehicle design from the control-related viewpoint. Nevertheless, the trade-off design of hypersonic vehicles is closely relevant to the anticipated waveriding 
operation point, leading to the limited optimization space for the fixed geometries. In turn, the optimally compromising relations between the flight performance and waveriding condition are difficult to obtain throughout the large flight envelope; especially for hypersonic vehicles the waveriding properties are restricted by the angle of attack, sideslip angle, and dynamic pressure in response of the different operation points. As a result, some new concepts are needed to introduce for the hypersonic vehicle design to improve robust stability over the large waveriding range, including the moving centroid control mode, reaction control strategies, and morphing techniques.

Morphing air vehicles are a concept that uses geometric changes to adapt to multipoint mission environments and improve overall performance [10]. Specifically, an aircraft with the variable wing geometry is considered for the mission-specific optimization and for enhanced maneuverability as well in [11], and large and rapid changes in the wing geometry will result in a significant change in flight dynamics such that the expected overall performances are achieved. In addition, the optimal control methods are presented in [12] for the fully variable morphing wings, and at the same time a novel parallel mechanism is designed to significantly improve the flight performance of an aircraft. However, these morphing techniques tend to be adopted for the airplane with the low velocity, and few studies have attempted to combine hypersonic flight with morphing technologies due to the restricted aspects consisting of the feasible material, thermal protection, and multidisciplinary coupling design issue. In fact, some morphing ideas are introduced for the hypersonic vehicle design; for example, the variable inlets and exhaust nozzles are used to improve the propulsive efficient of the scramjet. Therefore, hypersonic vehicles designed with deformable surfaces might be a reality in the future so as to guarantee global stability and improve waveriding performance.

This paper will investigate the design problems with respect to the collaborative deformation using the control integrated methods for hypersonic waverider. First, a parametric model is built using hypersonic aerodynamic theories for acquiring the coupling relations between the deformation and flight dynamics. Second, a trade-off design is studied based on the static and dynamic characteristics. Furthermore, the collaborative deformations are investigated to realize the matched design with regard to the multidiscipline contents, and at the same time a flight control law is designed to suppress the uncertain disturbances in the morphing process. Finally, a simulation example is provided to verify the feasibility of the proposed methods for hypersonic vehicles.

\section{Parametric Modeling Associated with Collaborative Deformations}

The first work for conducting the collaborative deformation design is to establish the parametric model of hypersonic vehicles, involving the aerodynamic module, propulsive module, control module, structure module, and so on. These modules are strong coupling each other, and the mutual influence makes the nonlinear model exhibit the unstable,

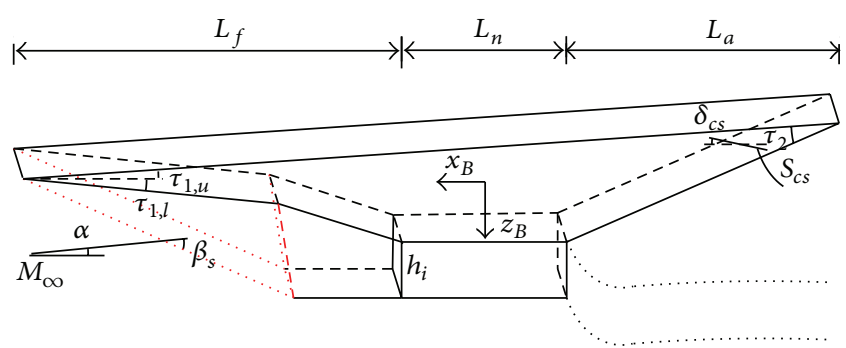

FIGURE 1: Typical waverider structure of hypersonic vehicles.

nonminimum, and time-varying features. Therefore, the exact description on these coupling relations is critical for hypersonic vehicles to understand their inherent dynamic characteristics, determining the control design space and feasible flight range. To obtain the parametric model, this paper uses a typical waverider structure, shown in Figure 1.

When the airflow enters into the lower forebody, the oblique shock wave theories are applied to estimate the shock angle $\beta_{s}$ in the concave surface [13]:

$$
\tan \beta_{s}=\frac{M_{\infty}^{2}-1+2 \lambda \cos [(4 \pi \delta+\arccos \chi) / 3]}{3\left(1+((\gamma-1) / 2) M_{\infty}^{2}\right) \tan \left(\tau_{1, l}+\alpha\right)}
$$

where

$$
\begin{aligned}
\lambda=( & \left(M_{\infty}^{2}-1\right)^{2}-3\left(1+\frac{\gamma-1}{2} M_{\infty}^{2}\right) \\
& \left.\left(1+\frac{\gamma+1}{2} M_{\infty}^{2}\right) \tan ^{2}\left(\tau_{1, l}+\alpha\right)\right)^{1 / 2}, \\
\chi= & \frac{1}{\lambda^{3}}\left[\left(M_{\infty}^{2}-1\right)^{3}-9\left(1+\frac{\gamma-1}{2} M_{\infty}^{2}\right)\right. \\
& \left.\cdot\left(1+\frac{\gamma-1}{2} M_{\infty}^{2}+\frac{\gamma+1}{4} M_{\infty}^{2}\right) \tan ^{2}\left(\tau_{1, l}+\alpha\right)\right],
\end{aligned}
$$

where $M_{\infty}$ denotes the flight Mach with respect to the free flow, $\alpha$ and $\gamma$ represent the angle of attack and ratio of specific heats, respectively, $\tau_{1, l}$ indicates the lower forebody turn angle, and $\delta$ is the coefficient associated with the shock wave. Alternatively, if the free flow reaches the upper forebody, the expansion wave relations are used for the convex surface, and it is expressed by [14]:

$$
\begin{gathered}
v(M)=\sqrt{\frac{\gamma+1}{\gamma-1}} \cdot \tan ^{-1} \sqrt{\frac{\gamma+1}{\gamma-1}\left(M^{2}-1\right)} \\
-\tan ^{-1} \sqrt{\left(M^{2}-1\right)}, \\
\tau_{1, l}+\alpha=v\left(M_{1}\right)-v\left(M_{\infty}\right),
\end{gathered}
$$




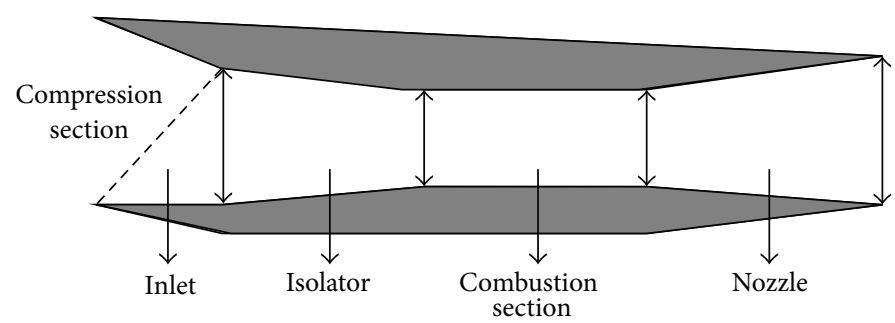

FIgUre 2: Propulsive structure.

where $M_{1}$ is the flight Mach of airflow passing the shock wave. Furthermore, the surface pressures and their coefficients $C_{p}$ using the oblique shock wave theories and expansion wave relations can be, respectively, expressed by

$$
\begin{gathered}
\frac{p_{1}}{p_{\infty}}=1+\frac{2 \gamma}{\gamma+1}\left(M_{\infty}^{2} \sin ^{2} \beta_{s}-1\right), \\
C_{p}=\frac{4}{\gamma+1}\left(\sin ^{2} \beta_{s}-\frac{1}{M_{\infty}^{2}}\right), \\
\frac{p_{1}}{p_{\infty}}=\left(\frac{2+(\gamma-1) M_{\infty}^{2}}{2+(\gamma-1) M_{1}^{2}}\right)^{\gamma /(\gamma-1)}, \\
C_{p}=\frac{2}{\gamma M_{\infty}^{2}}\left[\left(1-\frac{\gamma-1}{2} M_{\infty}|\delta|\right)^{2 \gamma /(\gamma-1)}-1\right] .
\end{gathered}
$$

Accordingly, the pressures can be gotten for all surfaces in Figure 1; thus the aerodynamic forces can be calculated by the superposition of these surface forces. Beyond this, the surface friction exists due to the viscous property as a result that the induced force $\tau_{w}$ is approximately computed by [15]

$$
\begin{gathered}
\tau_{w}=0.5 \rho^{*} V_{q}^{2} c_{f}, \\
c_{f}=\frac{0.0592}{\left(\operatorname{Re}^{*}\right)^{0.2}}, \\
\operatorname{Re}^{*}=\frac{\rho^{*} V_{q} x_{q}}{\mu^{*}},
\end{gathered}
$$

where

$$
\begin{gathered}
T^{*}=T_{q}\left[1+0.032 M_{q}+0.58\left(\frac{T_{w}}{T_{q}}-1\right)\right], \\
\rho^{*}=\frac{P_{q}}{R T^{*}} \\
\mu^{*}=\mu_{0}\left(\frac{T^{*}}{T_{0}}\right)^{3 / 2} \frac{T_{0}+110}{T^{*}+110}
\end{gathered}
$$

where $V_{q}$ and $M_{q}$ are, respectively, the flight velocity and Mach with respect to the boundary, $T_{q}$ and $P_{q}$ denote the temperature and pressure with respect to the boundary, respectively, and $x_{q}$ and $T_{w}$ indicate the distance from the leading edge and temperature on the surface.
Besides these aerodynamic forces, the propulsive force is necessary to be estimated for establishing the parametric model, and the according propulsive structure is shown in Figure 2.

This paper applies a 2D inlet model shown, and the combustion chamber is assumed as the average cross section. In this case, the airflow parameters in the combustion chamber, including the flight Mach $M$, pressure $P$, temperature $T$, speed $V$, and density $\rho$, can be expressed as a function along with $x$-axis, and they are provided by [16]

$$
\begin{aligned}
\frac{d M}{d x}=\frac{M \psi}{1-M^{2}}[ & -\frac{1}{A} \frac{d A}{d x}+\frac{1+\gamma M^{2}}{2 T_{t}} \frac{d T_{t}}{d x} \\
& \left.+\frac{1+\gamma M^{2}-y \gamma M^{2}}{\dot{m}} \frac{d \dot{m}}{d x}+\gamma M^{2} \frac{2 C_{f}}{D}\right], \\
\frac{d P}{d x}=\frac{P \gamma M^{2}}{1-M^{2}}[ & \frac{1}{A} \frac{d A}{d x}-\frac{\psi}{T_{t}} \frac{d T_{t}}{d x}-\frac{2 \psi(1-y)+y}{\dot{m}} \frac{d \dot{m}}{d x} \\
& \left.-\frac{1+(\gamma-1) M^{2}}{2} \frac{4 C_{f}}{D}\right], \\
\frac{d T}{d x}= & \frac{1}{\psi} \frac{d T_{t}}{d x}-\frac{(\gamma-1) T M}{\psi} \frac{d M}{d x},
\end{aligned}
$$

where $\psi=1+((\gamma-1) / 2) M^{2}$ and $A$ and $d A / d x$ are, respectively, the cross-sectional area and its change rate along with $x$-axis, $T_{t}$ and $d T_{t} / d x$ denote the total airflow temperature and its change rate along with $x$-axis, $C_{f}$ and $D$ represent the friction coefficient regarding the engine wall and airflow, respectively. Passing through the combustion chamber, the airflow enters the internal nozzle, and the according parameters are determined by

$$
\begin{gathered}
\frac{d M}{d x}=\frac{M \psi}{1-M^{2}}\left(-\frac{1}{A} \frac{d A}{d x}+\gamma M^{2} \frac{2 C_{f}}{D}\right), \\
\frac{d P}{d x}=\frac{P \gamma M^{2}}{1-M^{2}}\left[\frac{1}{A} \frac{d A}{d x}-\frac{1+(\gamma-1) M^{2}}{2} \frac{4 C_{f}}{D}\right], \\
\frac{d T}{d x}=\frac{(1-\gamma) T M^{2}}{1-M^{2}}\left(-\frac{1}{A} \frac{d A}{d x}+\gamma M^{2} \frac{2 C_{f}}{D}\right) .
\end{gathered}
$$




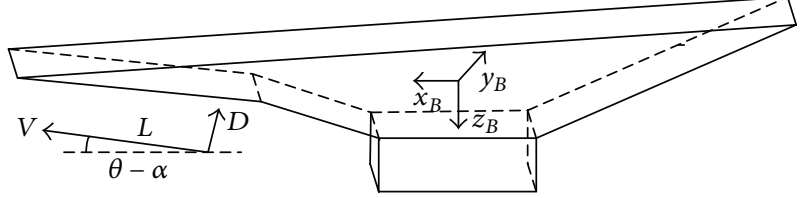

FIGURE 3: Matching relations of aerodynamic forces.

If $M_{4}, P_{4}$, and $T_{4}$ are selected as the inputs of the internal nozzle, based on (9), the according outputs $M_{5}, P_{5}$, and $T_{5}$ can be acquired. Afterwards, these outputs are considered as the inputs of the inputs of the external nozzle; the pressure is decided by [17]

$$
P_{a}=\frac{P_{5}}{1+\left(P_{5} / P_{\infty}-1\right) s_{a} / L_{a}},
$$

where $L_{a}$ denotes the external nozzle length along with the $x$-axis and $s_{a}$ is the length of the lower surface of the external nozzle. As soon as the propulsive parameters are gotten, the thrust can be estimated using the momentum theorem, and it is expressed by [18]

$$
T=\dot{m}_{a} V_{1}-\dot{m}_{a}\left(1+\phi f_{s t}\right) V_{5}+P_{5} A_{5}+P_{1} A_{1}
$$

Correspondingly, the lift due to the propulsive action is computed by

$$
L_{T}=\dot{m}_{a}\left(1+\phi f_{s t}\right) V_{5} \sin \theta_{\text {not }} \cos \alpha
$$

where $\theta_{\text {not }}$ is the angle between the airflow direction and the engine axis. After getting these aerodynamic forces and thrusts, we can substitute them into the nonlinear model of hypersonic vehicles such that the relations between the control inputs and flight states can be identified.

Furthermore, based on the matching relations of the aerodynamic forces in Figure 3, the established model of the hypersonic waverider is expressed by [19]

$$
\begin{gathered}
\dot{V}=-g \sin (\theta-\alpha)-\frac{D-T \cos \alpha}{m}, \\
\dot{\alpha}=q+\left(\frac{g}{V}-\frac{V}{R_{E}+h}\right) \cos (\theta-\alpha)-\frac{L+T \sin \alpha}{m V}, \\
\dot{h}=V \sin (\theta-\alpha), \quad \dot{q}=\frac{M}{I_{y}}, \quad \dot{\theta}=q,
\end{gathered}
$$

where $\theta$ and $\alpha$ are the flight pitch angle and angle of attack, respectively, and $m$ and $I_{y}$ denote the vehicle mass and moment of inertia, respectively. Nevertheless, the estimated aerodynamic forces and thrust are nonanalytic, leading them to be difficult for use in the control law design. Therefore, the analytic expressions with respect to the lift, drag, and thrust need to be acquired first; this paper applies the curvefitted means to obtain the nonlinear relations regarding the aerodynamic forces and thrust, which are given as [20]

$$
\begin{gathered}
L \approx \frac{1}{2} \rho V^{2} S C_{L}\left(\alpha, \delta_{\mathrm{e}}\right), \quad D \approx \frac{1}{2} \rho V^{2} S C_{D}\left(\alpha, \delta_{\mathrm{e}}\right), \\
M \approx z_{T} T+\frac{1}{2} \rho V^{2} S \bar{c}\left[C_{M, \alpha}(\alpha)+C_{M, \delta \mathrm{e}}\left(\delta_{\mathrm{e}}\right)\right] \\
T \approx C_{T}^{\alpha^{3}} \alpha^{3}+C_{T}^{\alpha^{2}} \alpha^{2}+C_{T}^{\alpha} \alpha+C_{T}^{0}
\end{gathered}
$$

where

$$
\begin{gathered}
C_{L}=C_{L}^{\alpha} \alpha+C_{L}^{0} \quad C_{D}=C_{D}^{\alpha^{2}} \alpha^{2}+C_{D}^{\alpha} \alpha+C_{D}^{0}, \\
C_{M, \alpha}=C_{M, \alpha}^{\alpha^{2}} \alpha^{2}+C_{M, \alpha}^{\alpha} \alpha+C_{M, \alpha}^{0}, C_{M, \delta_{e}}=c_{e} \delta_{e}, \\
C_{T}^{\alpha^{3}}=\beta_{1} \Phi+\beta_{2} C_{T}^{\alpha^{2}}=\beta_{3} \Phi+\beta_{4}, \\
C_{T}^{\alpha}=\beta_{5} \Phi+\beta_{6} C_{T}^{0}=\beta_{7} \Phi+\beta_{8} .
\end{gathered}
$$

Based on the acquired data, the trust region method is used to regulate these parameters for the curve-fitted expressions. In principle, it is expected that the fitting errors are small for the purpose of achieving the satisfactory matching relationship between the estimated data and the obtained fitting expressions. Under normal circumstances, the maximum standard residual index is provided to test this matching relation, and it is expressed by

$$
\operatorname{MSR}=\max _{i} \frac{r_{i}-\bar{r}_{i}}{\operatorname{std}\left(r_{i}\right)},
$$

where $r_{i}=C_{i}-\widehat{C}_{i}$ are the residuals, $\bar{r}_{i}$ denote the mean residuals, and $\operatorname{std}\left(r_{i}\right)$ represent the standard deviations of the residuals.

\section{Collaborative Deformations Analysis and Control Law Design}

The Taylor expansion is used for the nonlinear model in (13)(15) regarding the given flight point, and the resulting linear model is obtained as follows [21]

$$
\Delta \dot{x}=A \Delta x+B \Delta u
$$

where $\Delta x=[\Delta V, \Delta \alpha, \Delta h, \Delta q, \Delta \theta], \Delta u=\left[\Delta \delta_{e}, \Delta \Phi\right], A$ and $B$ indicate the linear model parameters. This study selects the lower forebody turn angle $\tau_{1, l}$ and the elevon area $S_{\delta}$ as the morphing variables. In principle, the change in the elevon area is caused by the airfoil uplift and wing contraction using the deformable material and retraction device to adjust overall performance. Alternatively, the change in the sweepback angle of the airfoil will lead to the effective elevon area altering accordingly. On the other hand, the change in the lower forebody turn angle $\tau_{1, l}$ has dramatic influence on the dynamic features for hypersonic vehicles. Furthermore, this angle change will affect the intensity and location of the 


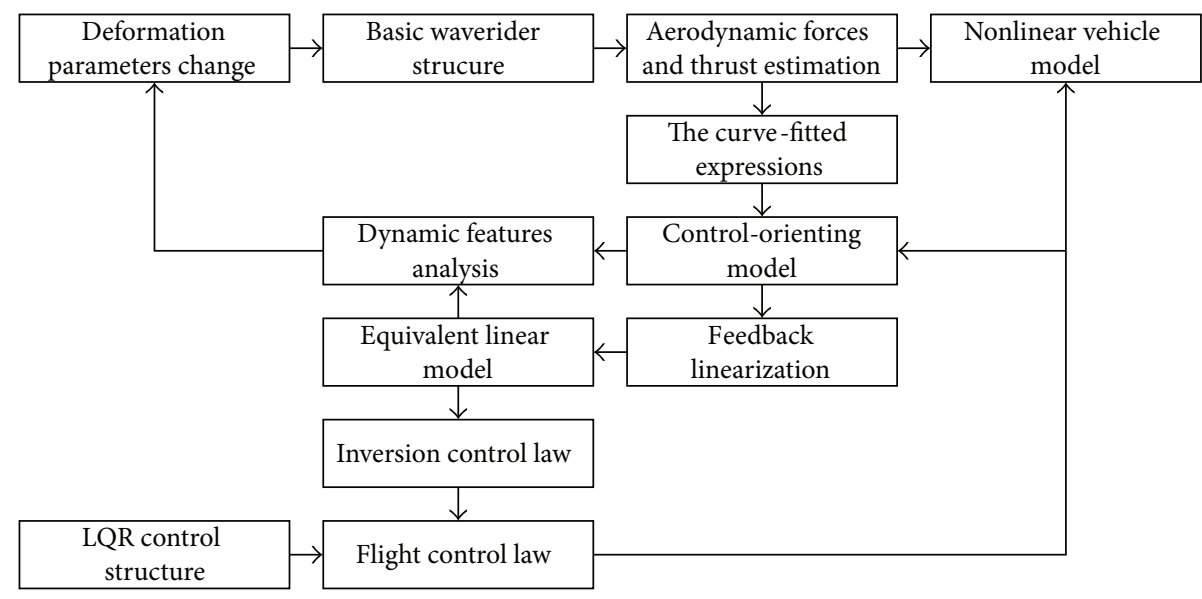

FIgURE 4: Overall study configuration of collaborative deformation design.

shock wave at the lower forebody surface, which determines the pressure and mass flow rate of the compressed airflow through the engine. Based on (1) and (4), when the angle of attack is given, the shock angle changes based on the variation in the lower forebody turn angle $\tau_{1, l}$ and the aerodynamic forces in relation to the resulting pressures are computed by

$$
L_{1}=P_{1} \cos \left(\tau_{1, l}+\alpha\right), \quad D_{1}=P_{1} \sin \left(\tau_{1, l}+\alpha\right) .
$$

Furthermore, according to (17), the performance effects due to the collaborative deformations are considered as a map from the parameter set $P$ to the continuous performance function $C$, given by

$$
f: \mathbf{p} \in \mathbf{P}^{n} \longrightarrow y \in \mathbf{C} .
$$

Accordingly, the sensitivity function of flight performances with respect to these morphing variables is shown as [22]

$$
S^{y}\left(\alpha, p_{i}\right)=\frac{\partial y}{d p_{i}}=S_{i}^{y}(\alpha),
$$

where $\partial y$ denotes the derivative with respect to the flight performance and $d p_{i}$ represents the derivative with respect to the $i$ th morphing variable. Furthermore, the norm of $S^{y}\left(\alpha, p_{i}\right)$ can be applied to conduct the quantitative analysis for these changes in the morphing parameters, and it is shown as

$$
s_{i}^{y}=\sqrt{\int\left|S_{i}^{y}(\alpha)\right|^{2} d \alpha} .
$$

Obviously, the larger $s_{i}^{y}$ denotes the sensitivity between the parameter $p_{i}$ and performance $y$ is more significant. Beyond this, the control action is needed to ensure flight stability in the morphing process. This paper adopts the feedback linearization approach and LQR control theory to design the flight control law for hypersonic waverider. In particular, we consider the propulsive system as a secondorder system where $\Phi_{c}$ is the equivalence ratio command. Furthermore, $\delta_{e}$ and $\Phi_{c}$ are selected as the control inputs, whereas $V$ and $h$ are considered as the system outputs. Following that, with the appropriate coordinate transformation

$$
z=\Gamma(x)=\left[V, L_{f} V, L_{f}^{2} V, h, L_{f} h, L_{f}^{2} h, L_{f}^{3} h\right]^{T} .
$$

Afterwards, the nonlinear model is transformed into the following equivalent linear model [3]:

$$
\begin{gathered}
\dot{z}_{1}=z_{2}, \quad \dot{z}_{2}=z_{3}, \\
\dot{z}_{3}=L_{f}^{3} V+\left(L_{\Phi_{c}} L_{f}^{2} V\right) \Phi_{c}+\left(L_{\delta_{e}} L_{f}^{2} V\right) \delta_{e}, \\
\dot{z}_{4}=z_{5}, \quad \dot{z}_{5}=z_{6}, \quad \dot{z}_{6}=z_{7}, \\
\dot{z}_{7}=L_{f}^{4} h+\left(L_{\Phi_{c}} L_{f}^{3} h\right) \Phi_{c}+\left(L_{\delta_{e}} L_{f}^{3} h\right) \delta_{e} .
\end{gathered}
$$

Based on (23), the inversion control law is obtained as

$$
\left[\begin{array}{l}
\Phi_{c} \\
\delta_{e}
\end{array}\right]=A(x)^{-1}\left[u_{V}-L_{f}^{3} V, u_{h}-L_{f}^{4} h\right]^{T}
$$

where

$$
A(x)=\left[\begin{array}{cc}
L_{\Phi_{c}} L_{f}^{2} V & L_{\delta_{e}} L_{f}^{2} V \\
L_{\Phi_{c}} L_{f}^{3} h & L_{\delta_{e}} L_{f}^{3} h
\end{array}\right],
$$

where $u_{V}=V^{(3)}$ and $u_{h}=h^{(4)}$. Furthermore, the LQR control structure is used to obtain the virtual signals $u_{V}$ and $u_{h}$, as shown in the following forms [23]:

$$
u_{V}(t)=V_{\mathrm{ref}}^{(3)}-K_{V}\left[\begin{array}{c}
V-V_{\mathrm{ref}} \\
L_{f} V-\dot{V}_{\text {ref }} \\
L_{f}^{2} V-\ddot{V}_{\mathrm{ref}} \\
\int_{0}^{t}\left[V(\tau)-V_{\mathrm{ref}}(\tau)\right] d \tau
\end{array}\right] .
$$

Correspondingly, the overall study configuration is given for the collaborative deformation design in Figure 4. 


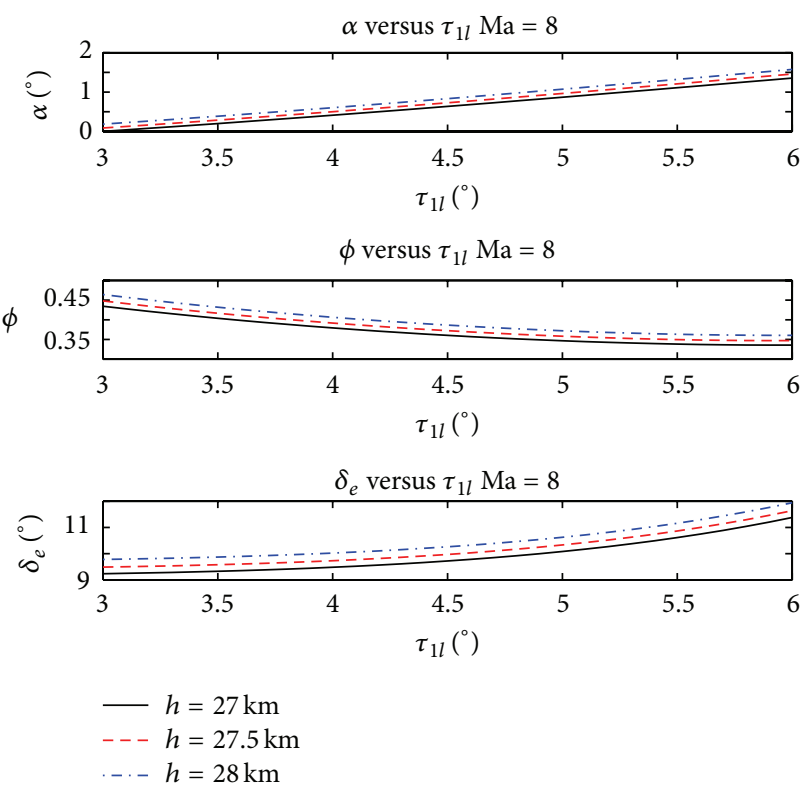

FIGURE 5: Trim angle of attack and control inputs with respect to lower forebody angle change.

Compared with the approaches and results in [20], this paper proposes a novel research process concerning the collaborative deformation design for the hypersonic waverider in Figure 4. This study includes the parametric modelling, model simplification, dynamic characteristic analysis, and control law design. In addition, the research contents in [20] aim to the control law design based on the control-orienting model using feedback linearization, and the control action can suppress the disturbance due to the elastic deformation which is passive and induced by the aerodynamic forces. By contrast, this paper presents a new idea that the active deformation and control action are both given for the hypersonic waverider to improve overall performance and guarantee flight stability through the large flight range. As a result, the collaborative deformation is required to realize the design goal for the hypersonic waverider.

\section{Simulation Analysis}

In the simulation, this paper uses the given geometric parameters of hypersonic waverider in [18], and the trim values due to the changes in lower forebody angle and elevon area are solved first to display the effect on static features with respect to the change in the different shape parameters. More importantly, the attention on the multivariable deformations is paid to discover the collaborative features associated with the different shape changes. Also, the control effectiveness is evaluated to guarantee overall stability in the morphing process.

Based on that, we first consider the change in the single shape parameter including the lower forebody angle and elevon area, and when the lower forebody angle changes from $3 \mathrm{deg}$ to $6 \mathrm{deg}$, the change curves of the trim angle of attack and control inputs are provided in Figure 5.
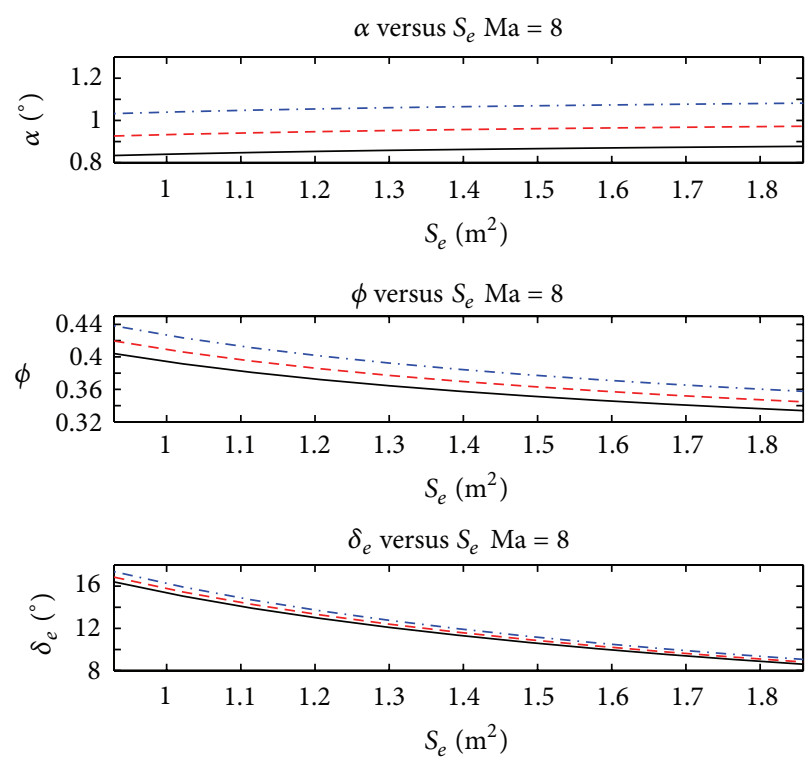

$$
\begin{aligned}
-h & =27 \mathrm{~km} \\
---h & =27.5 \mathrm{~km} \\
-\cdot-h & =28 \mathrm{~km}
\end{aligned}
$$

FIGURE 6: Trim angle of attack and control inputs with respect to elevon area change.

Figure 5 shows that the change in the lower forebody angle will have a significant influence on the trim angle of attack and control inputs. Not only that, when the elevon area alters, the change curves of the trim angle of attack and control inputs can be given in Figure 6 .

Figure 6 demonstrates the changes in the trim angle of attack and control inputs as the elevon area changes. We know that the according trends are converse in contrast to these provided in Figure 5. As a result, the collaborative deformation between the lower forebody angle and elevon area is necessary to consider, and the resulting relations are displayed in Figure 7.

Figure 7 tells us that the collaborative deformation between the lower forebody angle and elevon area will guarantee the matching trim relations between the flight states and control inputs. For instance, the trim equivalence ratio in Figure 7 will become smaller as lower forebody angle is larger. This is because that the compressed airflow through the engine will be affected by the increment of the lower forebody angle as a result of changing the trim equivalence ratio. In this case, the trim elevon deflection angle will become larger such that the according static properties are worse. Therefore, the matching relationship can be acquired by coordinating the geometric deformations in relation to the lower forebody angle and elevon area.

Furthermore, the inversion control law is applied to ensure flight stability and realize the command track. In the simulation, the command signals include $h_{c}=h_{0}+\Delta h=$ $27.1 \mathrm{~km}$ and $V_{c}=V_{0}+\Delta V=2477.8 \mathrm{~m} / \mathrm{s}$ where $h_{0}=27 \mathrm{~km}$ and $V_{0}=2397.8 \mathrm{~m} / \mathrm{s}$. When passing $100 \mathrm{~s}$, the response curves are provided in Figure 8. 


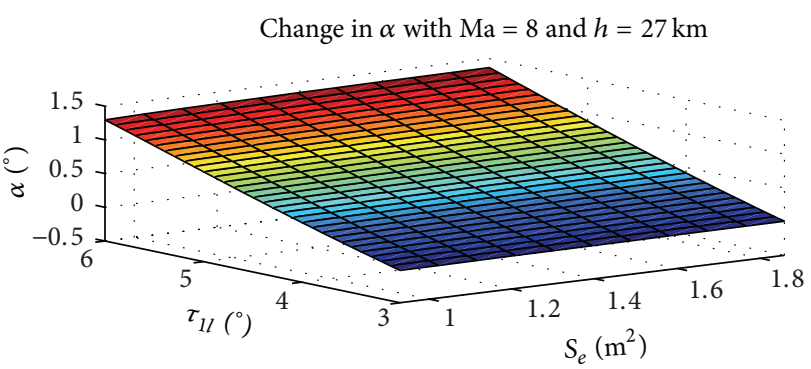

(a)

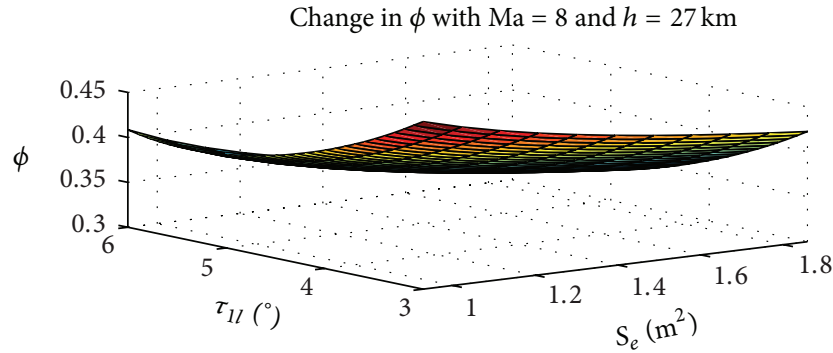

(b)

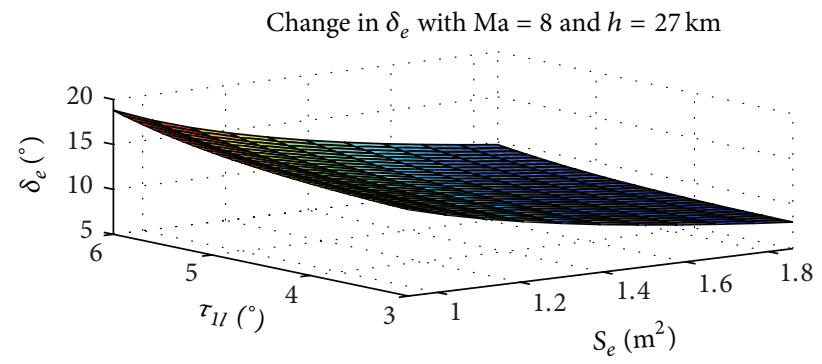

(c)

FIGURE 7: Collaborative relations between lower forebody angle change and elevon area change.

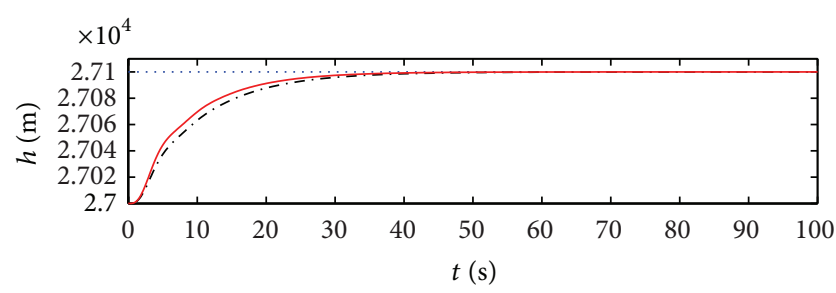

Altitude command

...- Altitude control response without deformation

Altitude control response with deformation

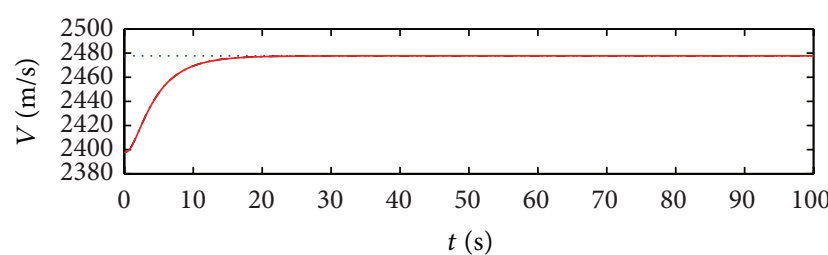

... Velocity command

. . - Velocity control response without deformation

_ Velocity control response with deformation

FIGURE 8: Response curves with respect to given command signals.

Figure 8 shows the outputs can follow the anticipated commands well on the conditions of with the collaborative deformation and without the collaborative deformation. These results indicate the response dynamics associated with the geometric deformation will become better than that associated with the fixed shape. Beyond this, the changes in the angle of attack and control inputs are given in Figure 9.
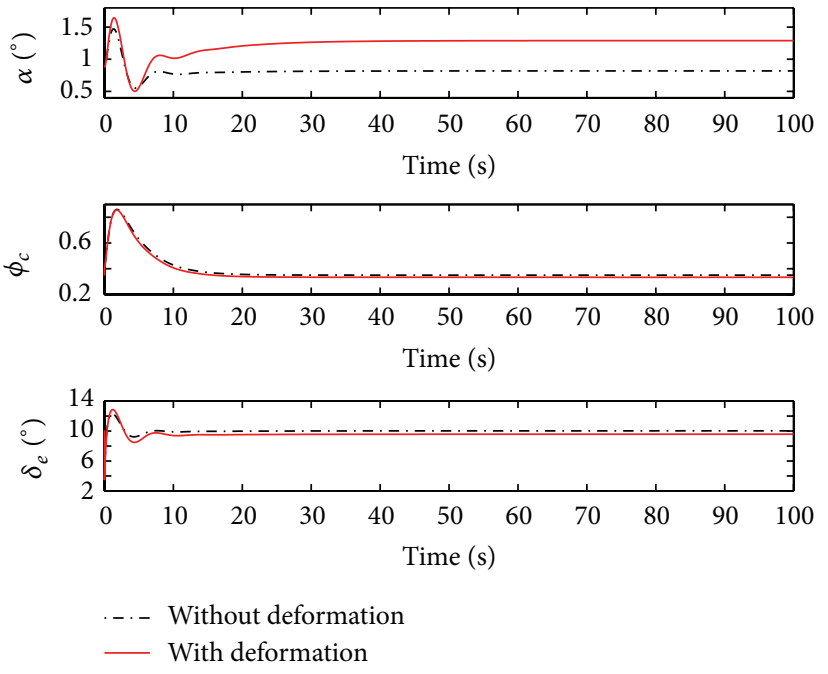

FIGURE 9: Changes in the angle of attack and control inputs.

Figure 9 demonstrates the changes in the angle of attack and control inputs when considering the control action. From these results, we note that the collaborative deformation makes that the equivalence ratio and elevon deflection angle are both smaller than that using the fixed structure. This will provide the more control redundancy and save the more energy for hypersonic waveriders in the control process. Specifically, by conducting the active deformation, the angle of attack can maintain the expected value of $1 \mathrm{deg}$ in order to meet the operation requirements of the scramjet. 


\section{Conclusion}

This paper investigates the collaborative deformation design problems for the hypersonic waverider. Although the typical structure of a hypersonic vehicle is used, the active deformation is considered with the changes in the lower forebody angle and elevon area. In addition, a control-related design framework is proposed for analyzing the effectiveness of the collaborative deformation of the hypersonic waverider, and this framework involves the multidisciplinary approaches, including aerodynamics, propulsion, and control. Furthermore, a simulation example is given to demonstrate that the collaborative deformation design is necessary to acquire the satisfactory performance through the overall envelope for the hypersonic waverider. We believe this work will be helpful to develop novel aerospace vehicles in the future.

\section{Conflict of Interests}

The authors declare that there is no conflict of interests regarding the publication of this paper.

\section{Acknowledgments}

This work is supported by National Natural Science Foundation of China under Grant no. 61403191, the open funding project of State Key Laboratory of Virtual Reality Technology and Systems under Grant nos. BUAA-VR-14KF-03 and BUAA-VR-14KF-06, and Natural Science Foundation of Jiangsu Province under Grant no. BK20130817. The authors thank the editors and the reviewers for their help and improvements to the quality of our presentation.

\section{References}

[1] T. Williams, M. A. Bolender, D. B. Doman et al., "An aerothermal flexible mode analysis of a hypersonic vehicle," in Proceedings of the AIAA Atmospheric Flight Mechanics Conference and Exhibit, Keystone, Colo, USA, August 2006.

[2] T. Skujins, C. E. S. Cesnik, M. W. Oppenheimer, and D. B. Doman, "Canard-elevon interactions on a hypersonic vehicle," Journal of Spacecraft and Rockets, vol. 47, no. 1, pp. 90-100, 2010.

[3] H. J. Xu, M. D. Mirmirani, and P. A. Ioannou, "Adaptive sliding mode control design for a hypersonic flight vehicle," Journal of Guidance, Control, and Dynamics, vol. 27, no. 5, pp. 829-838, 2004.

[4] Y. Liu, J. Deng, and Y. Lu, "Preliminary research on optimal design based on control demands for hypersonic morphing vehicle," IEEE Aerospace and Electronic Systems Magazine, vol. 28, no. 5, pp. 23-31, 2013.

[5] P. J. Ouzts, D. I. Soloway, D. Moerder, D. H. Wolpert, and J. Benavides, "The role of guidance, navigation, and control in hypersonic vehicle multidisciplinary design and optimization," in Proceedings of the 16th AIAA/DLR/DGLR International Space Planes and Hypersonic Systems and Technologies Conference, Norfolk, Va, USA, October 2009.
[6] C. E. Whitmer, A. G. Kelkar, J. M. Vogel, D. S. Chaussee, and C. J. Ford, "Control centric parametric trade studies for scramjet-powered hypersonic vehicles," in Proceedings of the AIAA Guidance, Navigation, and Control Conference, Toronto, Canada, August 2010.

[7] J. J. Dickeson, A. A. Rodriguez, S. Sridharan, and A. Korad, "Elevator sizing, placement, and control-relevant tradeoffs for hypersonic vehicles," in Proceedings of the AIAA Guidance, Navigation, and Control Conference, Toronto, Ontario, Canada, August 2010.

[8] A. G. Kelkar, J. M. Vogel, G. Inger, C. Whitmer, A. Sidlinger, and C. Ford, "Modeling and analysis framework for early stage trade-off studies for scramjet-powered hypersonic vehicles," in Proceedings of the 16th AIAA/DLR/DGLR International Space Planes and Hypersonic Systems and Technologies Conference, Norfolk, Va, USA, October 2009.

[9] A. G. Kelkar, J. M. Vogel, C. E. Whitmer, C. J. Ford, and D. S. Chaussee, "Design tool for control-centric modeling, analysis, and trade studies for hypersonic vehicles," in Proceedings of the 17th AIAA International Space Planes and Hypersonic Systems and Technologies Conference, San Francisco, Calif, USA, April 2011.

[10] T. A. Weisshaar, "Morphing aircraft systems: historical perspectives and future challenges," Journal of Aircraft, vol. 50, no. 2, pp. 337-353, 2013.

[11] B. Obradovic and K. Subbarao, "Modeling of flight dynamics of morphing-wing aircraft," Journal of Aircraft, vol. 48, no. 2, pp. 391-402, 2011.

[12] A. Moosavian, F. Xi, and S. M. Hashemi, "Design and motion control of fully variable morphing wings," Journal of Aircraft, vol. 50, no. 4, pp. 1189-1201, 2013.

[13] T. Skujins, C. E. S. Cesnik, M. W. Oppenheimer, and D. B. Doman, "Canard-elevon interactions on a hypersonic vehicle," Journal of Spacecraft and Rockets, vol. 47, no. 1, pp. 90-100, 2010.

[14] A. A. Rodriguez, J. J. Dickeson, O. Cifdaloz et al., "Modeling and control of scramjet-powered hypersonic vehicles: challenges, trends, and tradeoffs," in Proceedings of the AIAA Guidance, Navigation and Control Conference and Exhibit, Honolulu, Hawaii, USA, August 2008.

[15] L. V. Rudd and D. Pines, "Integrated propulsion effects on dynamic stability and control of hypersonic vehicles," in Proceedings of the 36th AIAA/ASME/SAE/ASEE Joint Propulsion Conference and Exhibit, Huntsville, Ala, USA, 2000.

[16] S. M. Torrez, J. K. Driscoll, D. J. Dalle, M. Bolender, and D. Doman, "Hypersonic vehicle thrust sensitivity to angle of attack and mach number," in Proceedings of the AIAA Atmospheric Flight Mechanics Conference, Chicago, Ill, USA, August 2009.

[17] F. R. Chavez and D. K. Schmidt, "Analytical aeropropulsive/aeroelastic hypersonic-vehicle model with dynamic analysis," Journal of Guidance, Control, and Dynamics, vol. 17, no. 6, pp. 1308-1319, 1994.

[18] M. A. Bolender and D. B. Doman, "Nonlinear longitudinal dynamical model of an air-breathing hypersonic vehicle," Journal of Spacecraft and Rockets, vol. 44, no. 2, pp. 374-387, 2007.

[19] L. Fiorentini, A. Serrani, M. A. Bolender, and D. B. Doman, "Nonlinear robust adaptive control of flexible air-breathing hypersonic vehicles," Journal of Guidance, Control, and Dynamics, vol. 32, no. 2, pp. 401-416, 2009. 
[20] J. T. Parker, A. Serrani, S. Yurkovich, M. A. Bolender, and D. B. Doman, "Control-oriented modeling of an air-breathing hypersonic vehicle," Journal of Guidance, Control, and Dynamics, vol. 30, no. 3, pp. 856-869, 2007.

[21] B. Xu and Z. K. Shi, "An overview on flight dynamics and control approaches for hypersonic vehicles," Science China Information Sciences, 2015.

[22] B. Q. Yang and Y. Y. Zhao, "Autopilot design method for the blended missile based on model predictive control," International Journal of Aerospace Engineering, vol. 2015, Article ID 718036, 13 pages, 2015.

[23] Q. Wang and R. F. Stengel, "Robust nonlinear control of a hypersonic aircraft," Journal of Guidance, Control, and Dynamics, vol. 23, no. 4, pp. 577-585, 2000. 

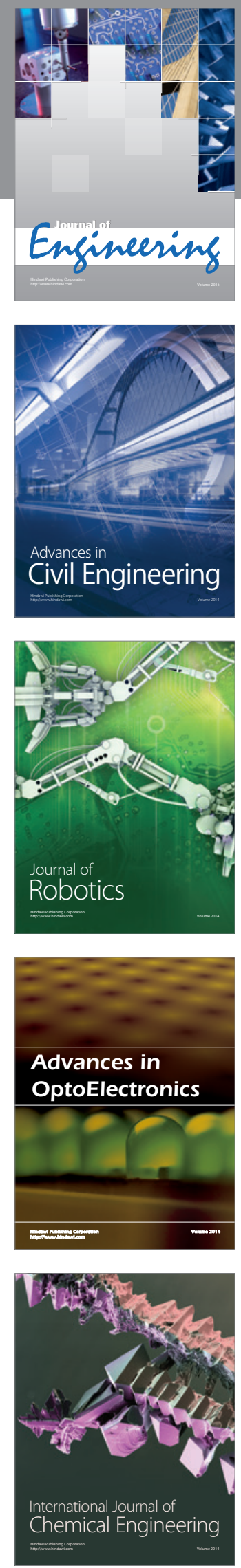

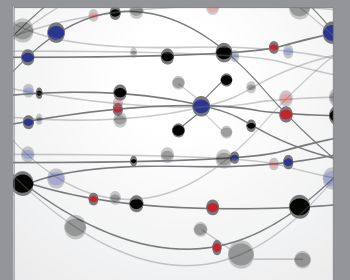

The Scientific World Journal
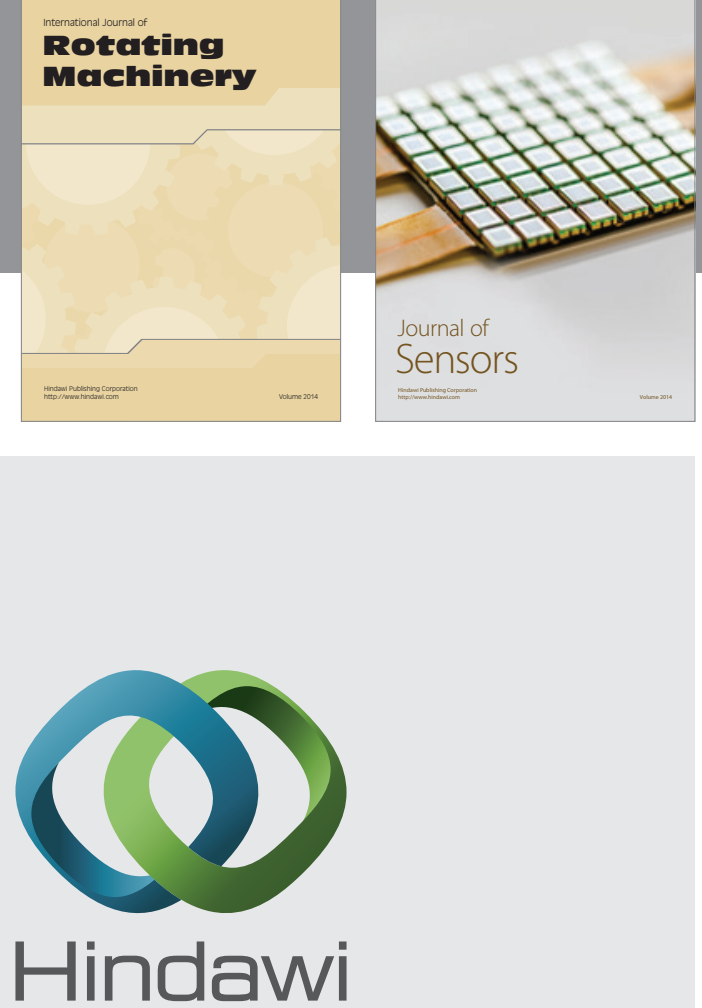

Submit your manuscripts at http://www.hindawi.com
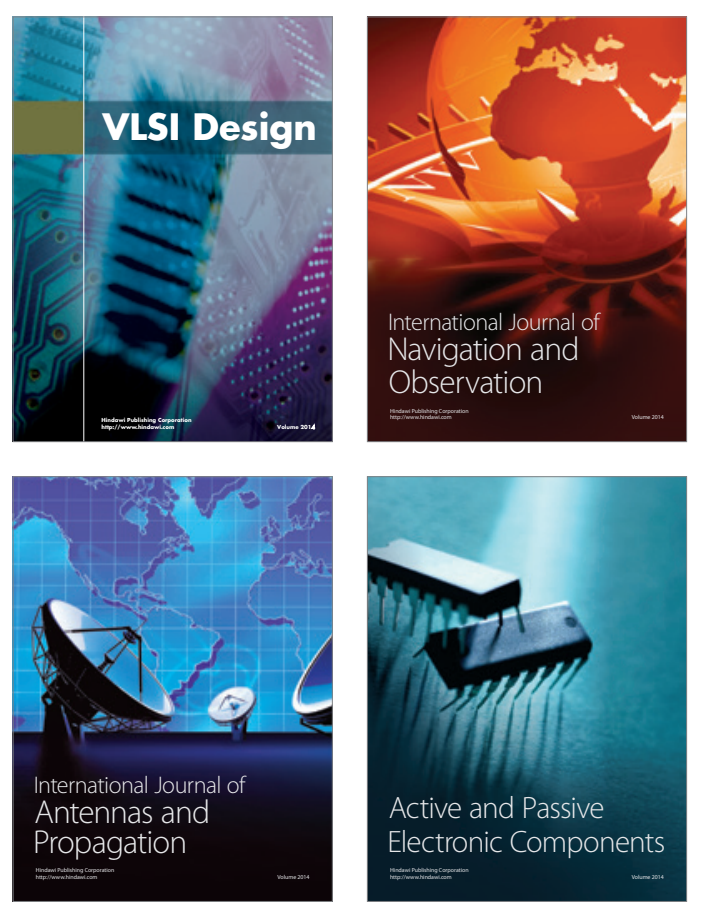
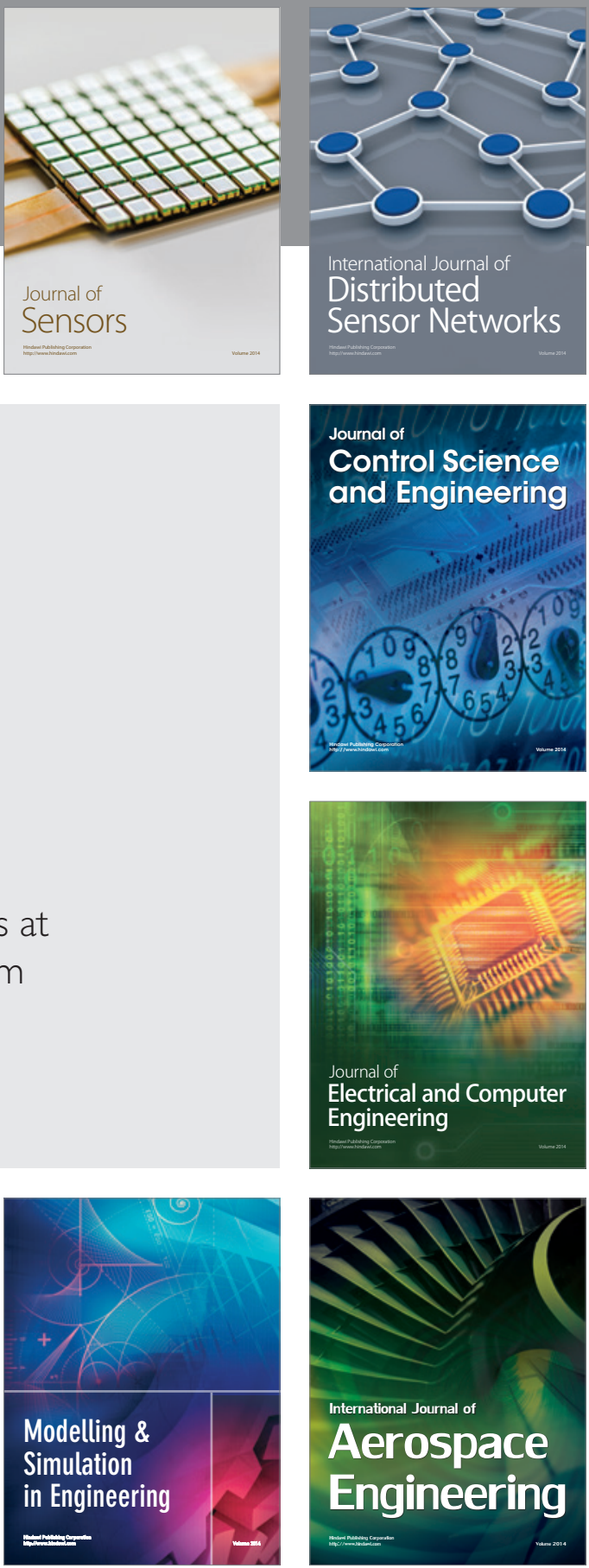

Journal of

Control Science

and Engineering
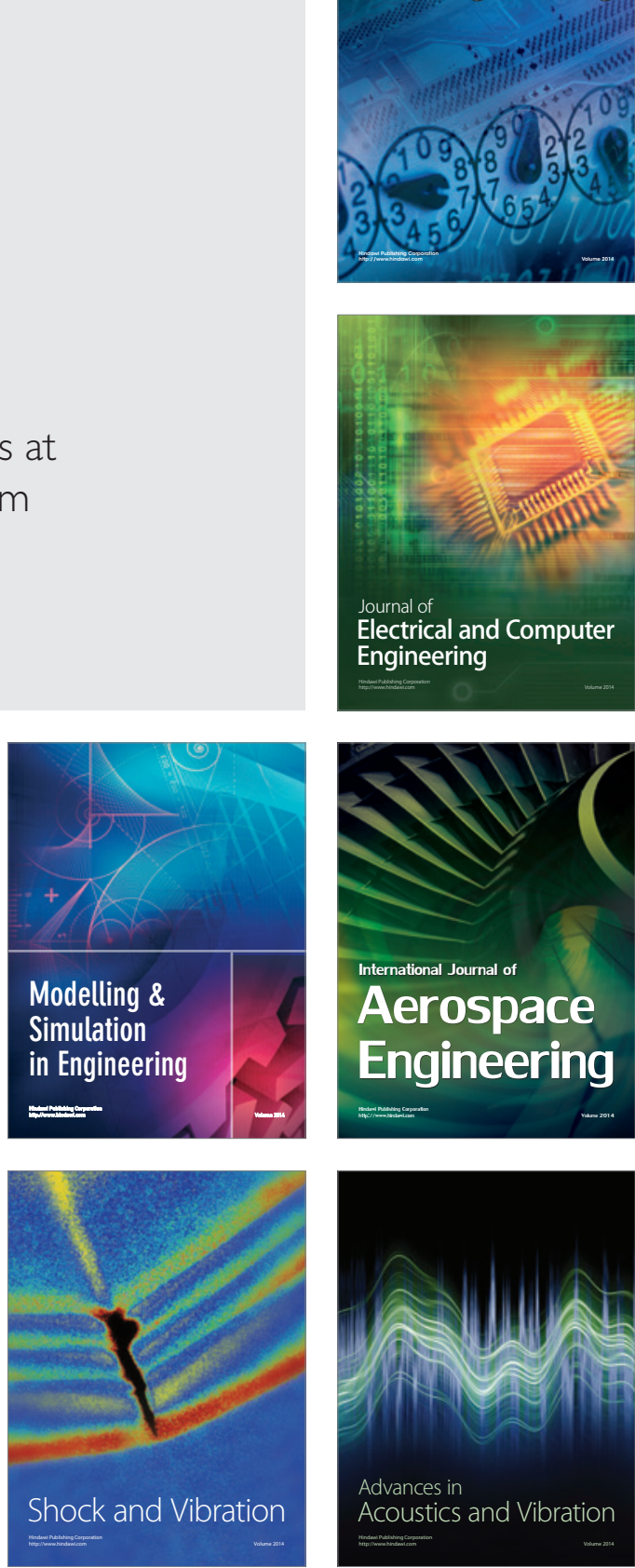